\title{
Correction: A pilot randomised blinded placebo-controlled trial of paracetamol for later treatment of a patent ductus arteriosus
}

\author{
Martin Kluckow ${ }^{1} \cdot$ Hazel Carlisle ${ }^{2} \cdot$ Margaret Broom $^{2} \cdot$ Patricia Woods $^{3} \cdot$ Michele Jeffery $^{1} \cdot$ Deepa Desai ${ }^{1} \cdot$ Yan Chen $^{1} \cdot$ \\ Nick Evans ${ }^{3}$
}

Published online: 14 November 2018

(c) Springer Nature America, Inc. 2018

Correction to: Journal of Perinatology https://doi.org/10. 1038/s41372-018-0247-z; published online 15 October 2018

In the published version of this paper the author Yan Chen was missed out of the author list. This has now been corrected in the HTML and PDF versions of the paper.
Martin Kluckow ${ }^{1}$ Hazel Carlisle ${ }^{2}$ Margaret Broom ${ }^{2}$ Patricia Woods ${ }^{3}$ Michele Jeffery ${ }^{1}$ Deepa Desai ${ }^{1}$ Yan Chen ${ }^{1}$ Nick Evans ${ }^{3}$

This has now been corrected in the HTML and PDF versions of the paper.

Martin Kluckow

martin.kluckow@sydney.edu.au

1 Department of Neonatology, Royal North Shore Hospital and

University of Sydney, Sydney, NSW, Australia

2 The Canberra Hospital, Canberra, ACT, Australia

3 Royal Prince Alfred Women and Babies Hospital and University of Sydney, Sydney, NSW, Australia 